\title{
Inertial Piezoelectric Rotary Motor Based on Low Profile Stator with Trapezoidal Waveguides
}

\author{
Ying YANG*, Andrius ČEPONIS**, Dalius MAŽEIKA***, Vytautas JŪRE்NAS** \\ *State Key Laboratory of Mechanics and Control Mechanical Structures, Nanjing University of Aeronautics and \\ Astronautics, Nanjing 210016, China, E-mail: yingyang@nuaa.edu.cn; (Corresponding author) \\ **Laboratory of Robotics and Piezomechanics, Institute of Mechatronics, Kaunas University of Technology, \\ K. Donelaičio st.73,LT-44249 Kaunas, Lithuania; E-mail: andrius.ceponis@ktu.lt (A.Č.); vytautas.jurenas@ktu.lt (V.J.) \\ ***Department of Information Systems, Faculty of Fundamental Sciences, Vilnius Gediminas Technical University, \\ Sauletekio al. 11,LT-10223 Vilnius, Lithuania,E-mail: dalius.mazeika@vgtu.lt
}

crossref http://dx.doi.org/10.5755/j02.mech.28247

\section{Introduction}

Inertial piezoelectric motors are widely used in modern mechatronic systems such as precise positioning devices, micro or nano handling systems, optical beam steering systems, zoom, focusing and image stabilization, scanning tunneling microscopy, etc. [1,2]. Widespread use of inertial piezoelectric motors is due to the following advantages: short response time, high resolution, self-locking, magnetic field-free operation, etc. [3, 4]. The inertial piezoelectric motors are classified into two groups based on operation principle i.e., stick-slip and slip-slip [5, 6]. The main difference between both operation principles is different acceleration between the stator and rotor at the contact surface that is caused by non - harmonic excitation signals of the motors. The saw tooth and square waveform signals are the most commonly used to drive inertial piezoelectric motors. More complex signals such as saw-tooth with a plateau or cycloid signal can be used as well [7, 8]. Different designs of inertial motors are developed up to now and can be classified as linear and rotary type motors. Linear inertial motors tend to have a simple design and provide limited displacement of the slider, while rotary type motors usually have a more complex structure and ability to provide high angular resolution and unlimited angular displacement range. Such features of rotary motors are important for optical systems such as light beam polarization or intensity control systems and etc. [9-11].

Wang and et al proposed an inertial rotary motor for underwater applications [12]. The motor design was based on a bimorph ring, vibration waveguides in which one of the ends was connected to the inner surface of the ring while other ends were connected to the hollowed tube, which was placed at the center of the ring. The operation of the motor is based on slip - slip operation, which was obtained thru excitation of radial, in-plane vibrations of the bimorph ring. The vibrations of the ring are transferred to the inner hollowed tube via waveguides. In order to transfer vibrations of the tube, two rotors were preloaded to both ends. The slip - slip motion of the tube was obtained by saw tooth excitation signal and transferred to double rotor system via friction between the inner tube and rotors system. The authors performed numerical and experimental investigations and concluded that the proposed motor is able to propose $2200 \mathrm{r} / \mathrm{min}$ rotation speed at $150 \mathrm{~V}_{p-p}$ excitation voltage amplitude without external load. On the other hand, the authors mounted the motor to an underwater bot and achieved
$1200 \mathrm{r} / \mathrm{min}$ rotation speed of the shaft with propeller and, as a result, achieved $80 \mathrm{~mm} / \mathrm{s}$ velocity of the bot.

Zhang and et al reported on the hybrid rotary motor based on slip-stick and inchworm operation principles [13]. The motor's design was based on a triangular driving mechanism that can propose benefits of both slip-stick and inchworm operation principles. The hybrid motor operation ensures a clamping action during the stick phase and a releasing action during the slip phase. This hybrid operation principle ensures benefits from both operation principles i.e., higher holding force during stick stage and easer control of inchworm stage of operation. The authors performed a numerical and experimental investigation and reported that the proposed motor is able to provide $4 \mathrm{~N} / \mathrm{m}$ self - holding torque at $90 \mathrm{~V}$ and $2600 \mathrm{~Hz}$ under saw tooth excitation signal. Moreover, the prototype achieved $0.6 \mathrm{rad} / \mathrm{s}$ rotation speed while load torque was higher than $1.8 \mathrm{~N} / \mathrm{m}$.

Wang and et al reported on the rotary positioning stage based on the inertial slip-stick operation principle [14]. The proposed rotary stage is based on a flexible mechanism, rotor, and two piezo stacks. The proposed stage operates as a non - resonant system. The piezoelectric stacks are excited by low-frequency saw tooth signals, which ensure extraction and contraction of piezoelectric stacks and as a result of the whole flexible mechanism. Due to the excitation principle and friction between stator and rotor, the vibrations generated by piezoelectric stacks are transferred to the rotor, and as a result, rotation motion is generated. The authors performed numerical and experimental investigations and concluded that the proposed system is able to provide 151 . $4 \mathrm{mrad} / \mathrm{s}$ at a frequency range from $1 \mathrm{~Hz}$ to $6000 \mathrm{~Hz}$. Moreover, the results show that proposed design is able to provide good performance and can be controlled by a simple control system.

A novel design of the piezoelectric inertial rotary motor is presented in this paper. The operation of the motor is described, and a numerical study based on finite element modeling is performed. A prototype motor was made, and an experimental study is performed to evaluate the output characteristics of the motor. Finally, the corresponding conclusions are provided.

\section{Design and operation principle of the motor}

The inertial piezoelectric motor consists of a square-shaped bimorph type stator, two-sided conical rotor, shaft, preloading spring, and spring clamper (Fig. 1). The 
passive layer of the stator is made from DIN 1.4301 stainless steel and has four bimorph plates that form a square-shaped frame. Four trapezoidal waveguides are placed in the center of each bimorph plate and are used to transfer in-plane bending vibrations of the plates to the rotation by employing the friction force between stator and rotor. In addition, two alumina oxide plates are glued on the top and bottom of the free ends of the waveguides. It allows to increase contact stiffness between the rotor and the waveguides. Totally sixteen piezo ceramic plates are glued on the top and bottom of the plates. The electrode of each piezo ceramic plate was divided into half, so a total of thirty-two electrodes were obtained. Such a configuration of the electrodes was used in order to excite the second in-plane bending mode employing $\mathrm{d} 31$ piezoelectric effect. The polarization direction of the piezo ceramic is aligned with the thickness, while the polarization of upper and lower piezo ceramic plates are pointed to opposite directions.

A two-sided conical rotor, which is made from C17200 beryllium bronze, is placed at the center of the sta-

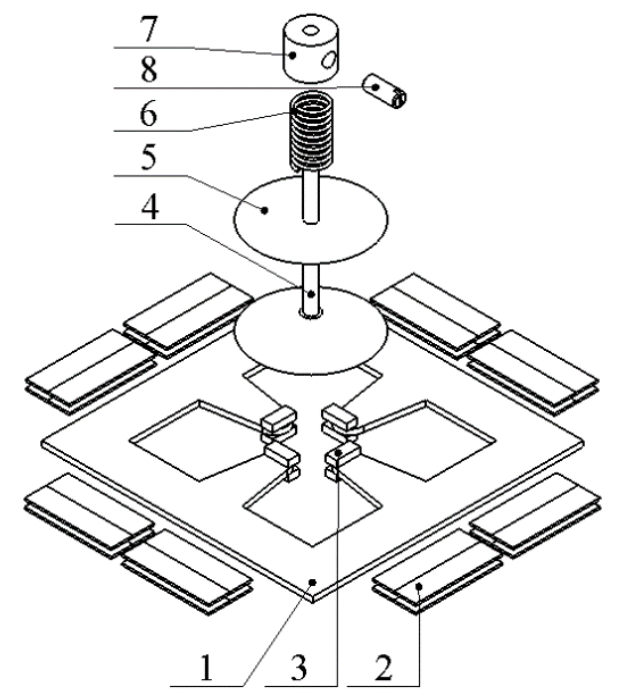

a tor and is in contact with trapezoidal waveguides thru alumina oxide plates. Two cones of the rotors are located on the shaft and preloaded against each other by the spring. The cylindrical clamper is used to fix the position of the spring on the shaft and adjust the preloading force. The proposed structure of the rotor does not require ball bearings for shaft holding. Therefore, the total size of the device becomes smaller. The sketch of the stator and the list of geometrical parameters are given in Fig. 2 and Table 1. The main advantage of the proposed actuator design is the compact size and small thickness. The actuator can be integrated into a printed circuit board and used for the small size positioning devices where space is limited. Moreover, the actuator size can be scaled and adjusted to the specific requirements of the application. In addition, the clamping of the motor is implemented via neodymium magnets which are placed at each corner of the motor. Such way of the clamping, in comparison to clamping via bolts, ensures lower structural damping of the motor and by this way increases output characteristics.

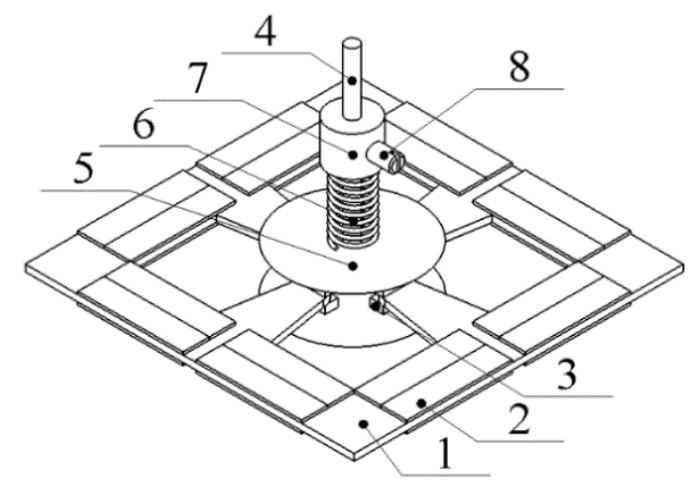

b

Fig. 1 Design of the motor; $\mathrm{a}$ - exploded view; $\mathrm{b}$ - isometric view of the assembled motor; 1 - stator; 2 - piezo ceramic plates; 3 - alumina oxide block; 4 - shaft; 5 - two-sided conical rotor; 6 - preload spring; 7 - clamper of preload spring; 8 - bolt for fixing clamper of preload spring

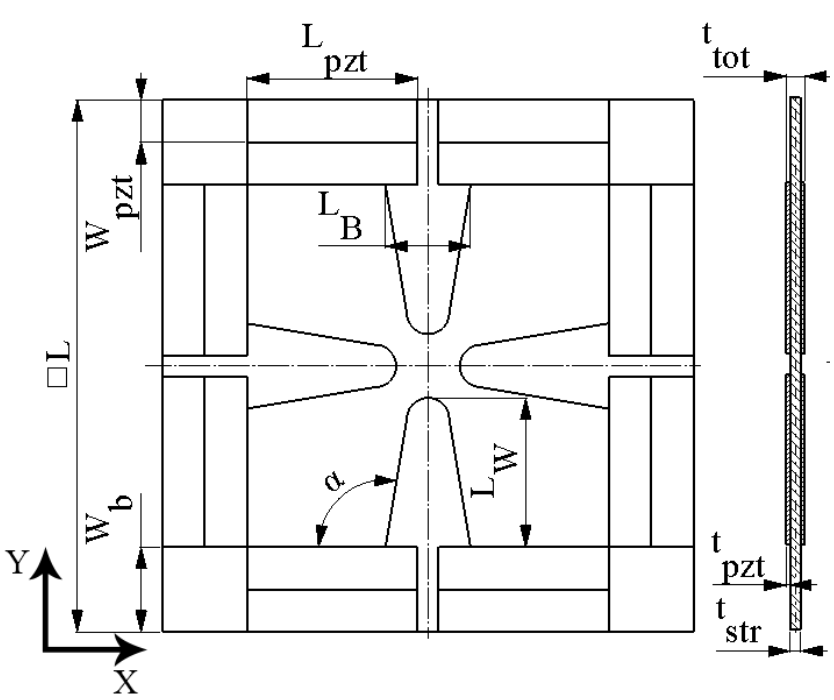

Fig. 2 Sketch of the stator

Table 1

Geometrical parameters of the stator

\begin{tabular}{|c|c|c|}
\hline $\begin{array}{c}\text { Parame- } \\
\text { ter }\end{array}$ & $\begin{array}{c}\text { Value, } \\
\mathrm{mm}\end{array}$ & Description \\
\hline$L$ & 25 & Length of the stator \\
\hline$L_{p z t}$ & 8 & Length of piezo ceramic plate \\
\hline$L_{w}$ & 5.5 & Length of trapezoidal waveguide \\
\hline$L_{B}$ & 3 & $\begin{array}{c}\text { Length of trapezoidal waveguide } \\
\text { base }\end{array}$ \\
\hline$W_{p z t}$ & 2 & Width of piezo ceramic plate \\
\hline$W_{b}$ & 4 & Width of beam \\
\hline$t_{t o t}$ & 0.9 & The total thickness of motor \\
\hline$t_{p z t}$ & 0.2 & $\begin{array}{c}\text { The thickness of piezoceramic } \\
\text { plate }\end{array}$ \\
\hline$t_{s t r}$ & 0.5 & Thickness of stator \\
\hline$\alpha$ & $100^{\circ}$ & $\begin{array}{c}\text { An inclination angle of the wave- } \\
\text { guide }\end{array}$ \\
\hline
\end{tabular}

The operation principle of the motor is based on the stick-slip principle. The second in-plane bending mode 
of the bimorph plates is employed to obtain in-plane oscillations of the waveguides. Two saw tooth waveform signals with shifted phased by $\pi$ are applied on the electrodes to obtain asymmetrical oscillations of the waveguides. The excitation scheme of the piezoelectric plates is shown in Fig. 3. It can be seen that piezo ceramic plates are divided into two groups and are exited using electric signals that phase differs by $\pi$.

The slow forced in-plane bending of the bimorph plates is excited during the electric signal rising phase, and the slow-motion of the waveguides is obtained. The rotor is rotated by a particular angle because of the friction force that is larger than the inertial force of the rotor, and the stick phase of the motor is induced. During the electric signal falling phase, the bimorph plate rapidly bends in the opposite direction, and waveguides move in the opposite direction with higher velocity. The rotor slips to the stator because the inertial force prevents the rotor from following the motion of the waveguides. The rotor can be rotated constantly by repeating stick-slip motions continuously. The reversible motion of the rotor can be obtained by changing the phase order of the slow and the fast motion of the bimorph plates. In order to fully represent operation principle of the motor, vibration sequence in one period $(T)$ is given in Fig. 5. The friction force is very important for output velocity and torque values of the motor. Friction force can be controlled via preload force induced by the spring and clamper position (Fig. 1, a). Also, the velocity difference between contacting surfaces of the stator and rotor influences the transition between static and dynamic friction coefficients and friction force as well. The velocity of the contact surface can be con- trolled by changing the amplitude and frequency of the electric signal.

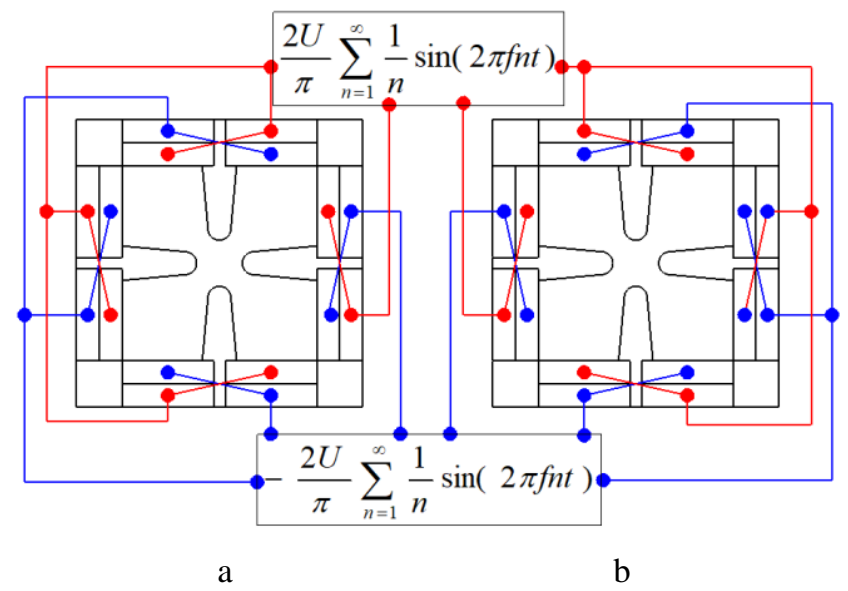

Fig. 3 Excitation schematics of the motor; $a-$ top view; $b-$ bottom view

\section{Numerical investigation of the motor}

Numerical investigation of the motor was performed in order to validate the operation principle to calculate modal shapes and resonant frequencies of the stator as well as to investigate the mechanical and electrical characteristics of the motor. The finite element model (FEM) was built using Comsol 5.4 software with respect to the geometrical parameters which are given in Table 1. Properties of the material used in the model are shown in Table 2.

Table 2

Materials properties

\begin{tabular}{|c|c|c|}
\hline Material properties & Stainless steel DIN 1.4301 & PI Ceramics PIC155 \\
\hline Density, $\mathrm{kg} / \mathrm{m}^{3}$ & 8000 & 7800 \\
\hline Young's modulus, $\mathrm{N} / \mathrm{m}^{2}$ & $10 \cdot 10^{9}$ & $7.6 \cdot 10^{10}$ \\
\hline Poisson`s coefficient & 0.3 & - \\
\hline Isotropic structural loss factor & 0.02 & - \\
\hline Relative permittivity & - & $\varepsilon_{11}{ }^{T} / \varepsilon_{0}=1200$ \\
& - & $\varepsilon_{33}{ }^{T} / \varepsilon_{0}=1500$ \\
\hline Elastic compliance coefficient, $10^{-12} \mathrm{~m}^{2} / \mathrm{N}$ & - & $S_{11}{ }^{E}=15.00$ \\
& - & $S_{33}{ }^{E}=19.00$ \\
\hline Elastic stiffness coefficient $c_{33}{ }^{D}, \mathrm{~N} / \mathrm{m}^{2}$ & - & $1.6 \cdot 10^{10}$ \\
\hline Piezoelectric constant $d_{33}, 0^{-12} \mathrm{~m} / \mathrm{V}$ & - & 225 \\
\hline Piezoelectric constant $d_{31}, 10^{-12} \mathrm{~m} / \mathrm{V}$ & -97 \\
\hline Piezoelectric constant $d_{15}, 10^{-12} \mathrm{~m} / \mathrm{V}$ & - & 330 \\
\hline
\end{tabular}

Firstly, the optimization of the stator design was performed. The optimization problem was set up to find the optimal total length and base length of the trapezoidal waveguide. The objective of the problem was to maximize displacements amplitudes in $\mathrm{X}$ and $\mathrm{Y}$ directions at the contact tips i.e. one contact tip is parallel to $\mathrm{X}$ axis while another is parallel to Y axis.

Two optimization problems were solved sequentially, that is, optimal values were found when displacements amplitudes in $\mathrm{X}$ and $\mathrm{Y}$ directions were maximized. The optimization problem is described as follows:

$$
\begin{aligned}
& \underset{L_{W}, L_{B}}{\max }=u_{x}\left(L_{W}, L_{B}\right), \\
& \max _{L_{W}, L_{B}}=u_{y}\left(L_{W}, L_{B}\right),
\end{aligned}
$$

subjected to:

$$
\begin{aligned}
& L_{W}^{\min } \leq L_{W} \leq L_{W}^{\max }, \\
& L_{B}^{\min } \leq L_{B} \leq L_{B}^{\max }, \\
& f_{\text {min }} \leq f \leq f_{\text {max }} .
\end{aligned}
$$

here: $u_{x}$ and $u_{y}$ are displacement amplitudes of two perpendicular waveguides in X and Y directions, respectively; $L_{W}$ is the total length of the waveguide; $L_{B}$ is the total length of the trapezoidal waveguide base; $L_{W}^{\min }$ and $L_{W}^{\max }$ are lower and upper limits of the total length of the waveguide; $L_{B}^{\min }$ and 
$L_{B}^{\max }$ are lower and upper limits of the total length of trapezoidal waveguide base; $f_{\min }$ and $f_{\max }$ are lower and upper limits of the analysed frequency range.

The following boundary conditions were set in the model i.e.; the corners of the stator were fixed rigidly in order to simulate clamping of the motor. Two saw tooth excitation signals were applied to the electrodes with respect to the scheme given in Fig. 3 while the voltage amplitude of $150 \mathrm{~V}_{p-p}$ was used. The steel frame of the stator was grounded as well as gravity force was included in the model. The lower and upper limits of the analysed frequency range $f_{\text {min }}$ and $f_{\text {max }}$ were set to $25 \mathrm{kHz}$ and $65 \mathrm{kHz}$, respectively. The step of the analysis was set to $25 \mathrm{~Hz}$. Moreover, lower and upper limits $L_{W}^{\min }$ and $L_{W}^{\max }$ of waveguide length were set to $3 \mathrm{~mm}$ and $6.5 \mathrm{~mm}$, respectively. Finally, lower and upper limits of waveguide base length $L_{B}^{\min }$ and $L_{B}^{\max }$ were set to 1 $\mathrm{mm}$ and $4 \mathrm{~mm}$, respectively. Both lengths were iterated with

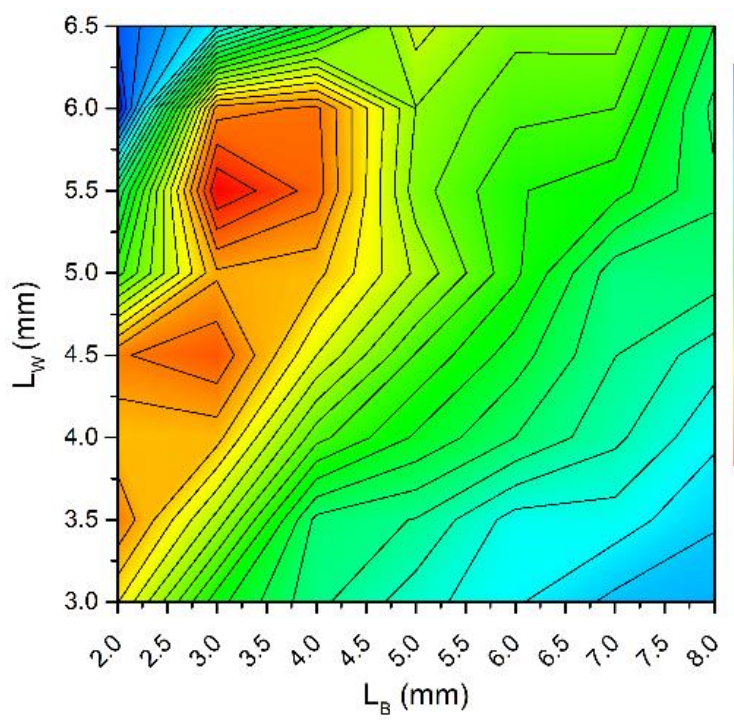

a

Fig. 4 The plot of objective function dependence from design variables; a - displacement of the waveguide in $\mathrm{X}$ direction; $\mathrm{b}$ - displacement of the waveguide in $\mathrm{Y}$ direction

As it can be found in Table 3, the highest displacement amplitudes were obtained in set No. 3. Comparing the results obtained using set No. 3 and No. 1, it can be seen that displacement amplitudes in $\mathrm{X}$ and $\mathrm{Y}$ directions are higher $31.4 \%$ and $9.36 \%$, respectively. Moreover, a comparison of the results between set No. 3 and No. 2 showed that displacement amplitudes in $\mathrm{X}$ and $\mathrm{Y}$ directions are higher by $14.02 \%$ and $15.74 \%$, respectively. Therefore, it can be concluded that the best values of design variables were obtained in set No. 3. The ratio between contact point displacement amplitudes in $\mathrm{X}$ and $\mathrm{Y}$ directions was calculated for all three sets. As it can be seen in Table 3, the largest ratio of 1.334 was obtained using set No. 1 while using set No. 2 is much smaller, i.e., 1.029. The difference between vibration amplitudes in $\mathrm{X}$ and $\mathrm{Y}$ direction was $0.8 \%$ when set No. 3 was used. It means that motion of the rotor will be even and smooth due to low difference in displacement amplitudes of different waveguides. Therefore, set No. 3 was selected for further numerical investigations. Graphical representation of the operating principle is given in Fig. 5 where vibration shapes of the stator are shown during one vibration period $T$.

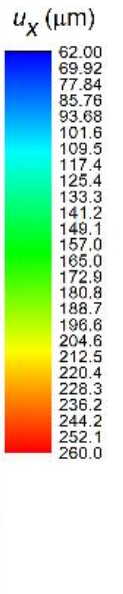

b

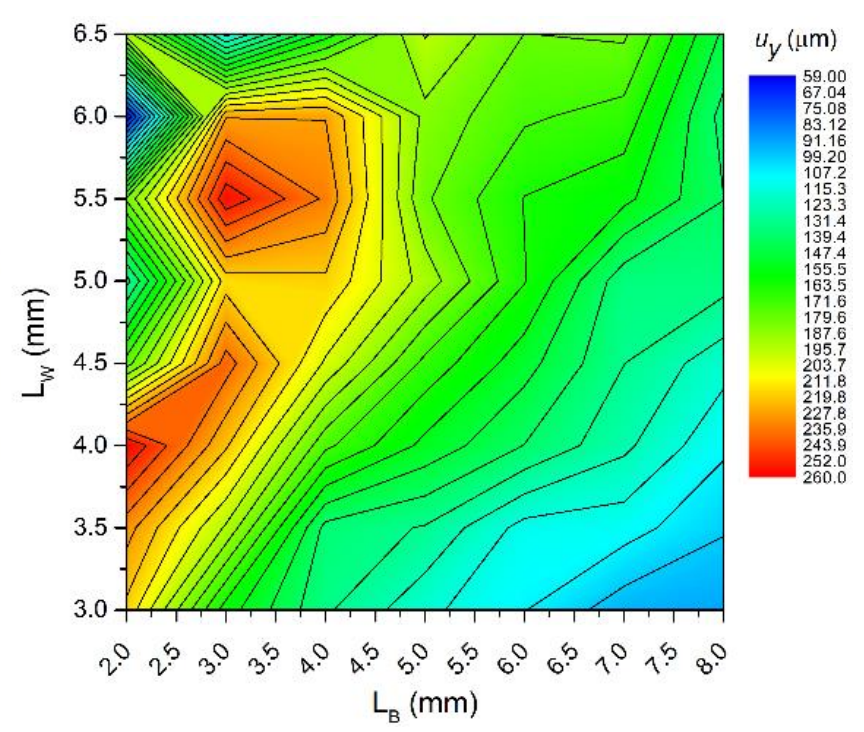

a step of $0.5 \mathrm{~mm}$. The results of the calculations are shown in Fig. 4, where the colour legend of the plot shows the values of the objective functions in micro-meters.

Three $L_{W}$ and $L_{B}$ sets were indicated while analysing the results of the optimization problem (Table 3 ). The highest displacement amplitudes in $\mathrm{X}$ or $\mathrm{Y}$ directions were obtained using these sets. The values of corresponding designs variable values, displacement amplitudes in $\mathrm{X}$ and $\mathrm{Y}$ directions, and the ratio of displacement amplitudes between $L_{W}$ and $L_{B}$ are given in Table 3.

Table 3

List of design variables and objective function values

\begin{tabular}{|c|c|c|c|c|c|}
\hline Set No. & $L_{W}, \mathrm{~mm}$ & $L_{B}, \mathrm{~mm}$ & $u_{x}, \mu \mathrm{m}$ & $u_{y}, \mu \mathrm{m}$ & $u_{x} / u_{y}$ \\
\hline 1 & 4 & 2 & 235.2 & 176.3 & 1.334 \\
\hline 2 & 4.5 & 3 & 223.1 & 216.8 & 1.029 \\
\hline 3 & 5.5 & 3 & 259.5 & 257.3 & 1.008 \\
\hline
\end{tabular}

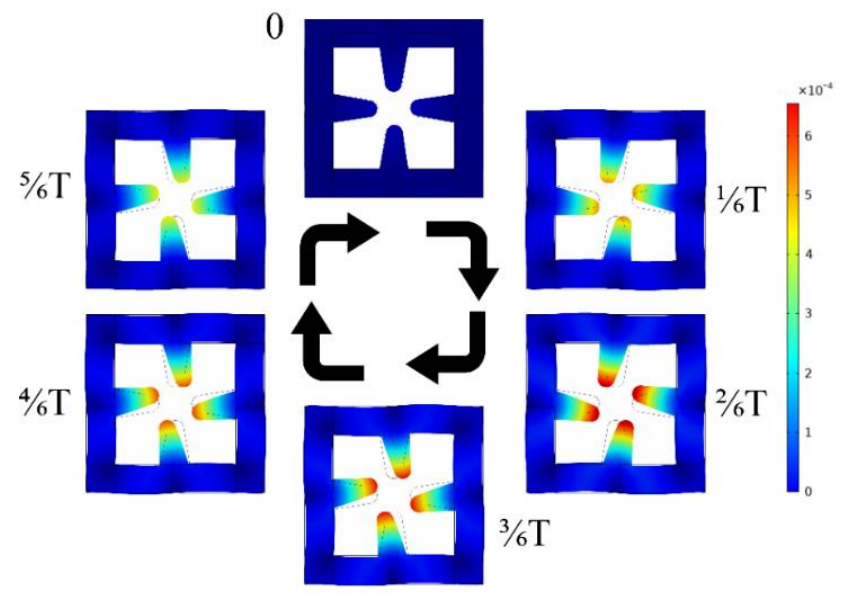

Fig. 5 Vibration sequence of the motor during one period while operation frequency is $46.38 \mathrm{kHz}$

Excitation of the motor was performed using the excitation scheme shown in Fig. 3. It can be seen that the 
second in-plane bending mode of the bimorph plates is excited, and trapezoidal waveguides bend in the same direction. Comparing the stator oscillation forms obtained at 1/6 $T$ and 5/6 $T$ time moments, it can be noted that the displacements of the contact points are not the same. This is indicated by the different colors of the contacting point's displacement (Fig. 5). It means that asymmetric oscillations of the contact points are induced and vibration velocity in for warding and backward directions are different. Therefore, the rotor is driven employing the inertial principle.

The next step of the numerical investigation was performed to indicate impedance-frequency and phase-frequency characteristics of the motor. The results of the numerical simulation are given in Fig. 6. It can be seen that the resonant frequency of the motor is $46.403 \mathrm{kHz}$. The calculated mechanical quality factor $Q_{m}$ of the motor is 3093.53 .

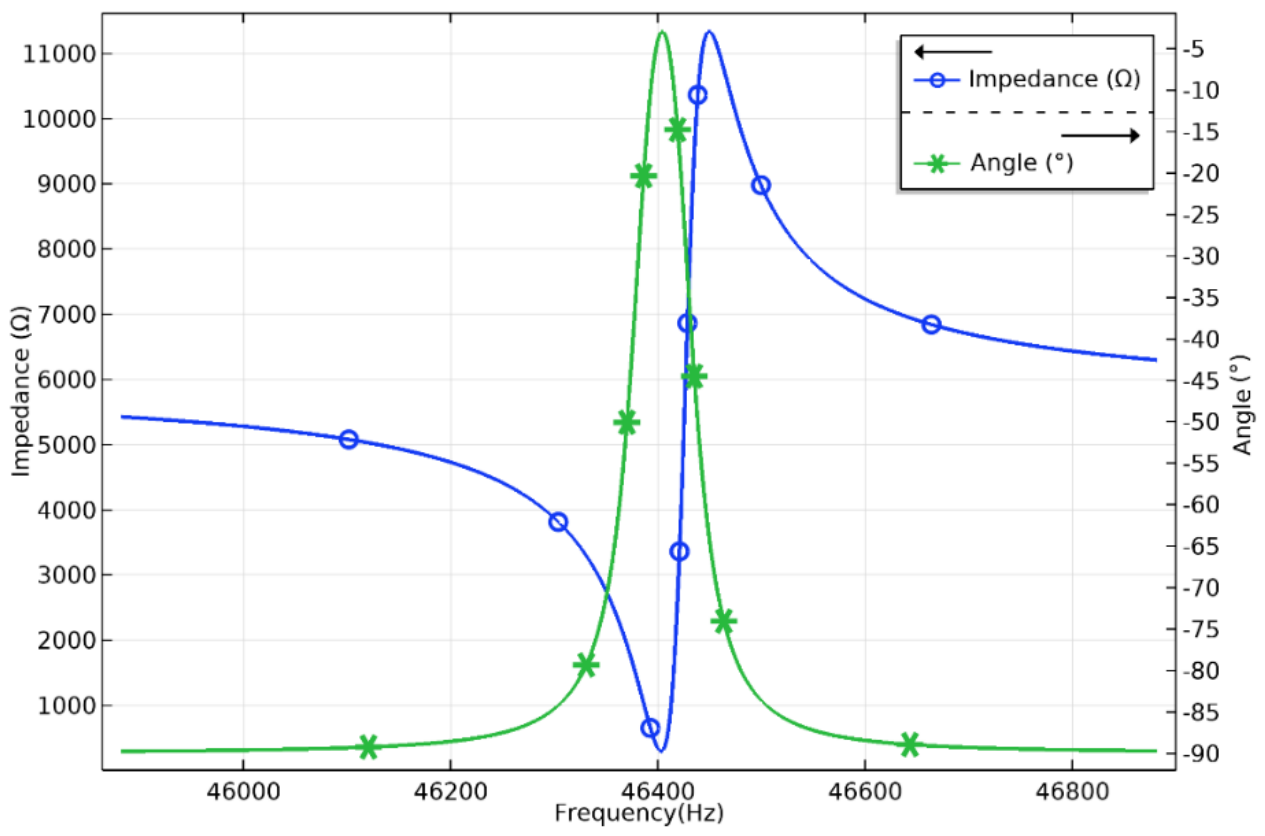

Fig. 6 Impedance and phase frequency characteristics of the motor

Contact point displacement and velocity in $\mathrm{X}$ and $\mathrm{Y}$ directions were analysed in the time domain as well. A time interval of five periods of steady-state vibrations was analysed. Vibration characteristics were investigated under different excitation voltage amplitudes i.e. from $20 \mathrm{~V}_{p-p}$ to $120 \mathrm{~V}_{p-p}$ with the step of $20 \mathrm{~V}_{p-p}$. The calculation of two waveguides which are normal to each other was based on intension to indicate differences in dynamic characteristics of contact points located on different waveguides. These differences can be cause of uneven rotation of rotor.

Firstly, the velocity of contact points in $\mathrm{X}$ and $\mathrm{Y}$ was calculated. The results are given in Fig. 7. The steadystate velocity of the contact points in $\mathrm{X}$ and $\mathrm{Y}$ directions was obtained after five periods of operation i.e., approximately after $110 \mu \mathrm{s}$.

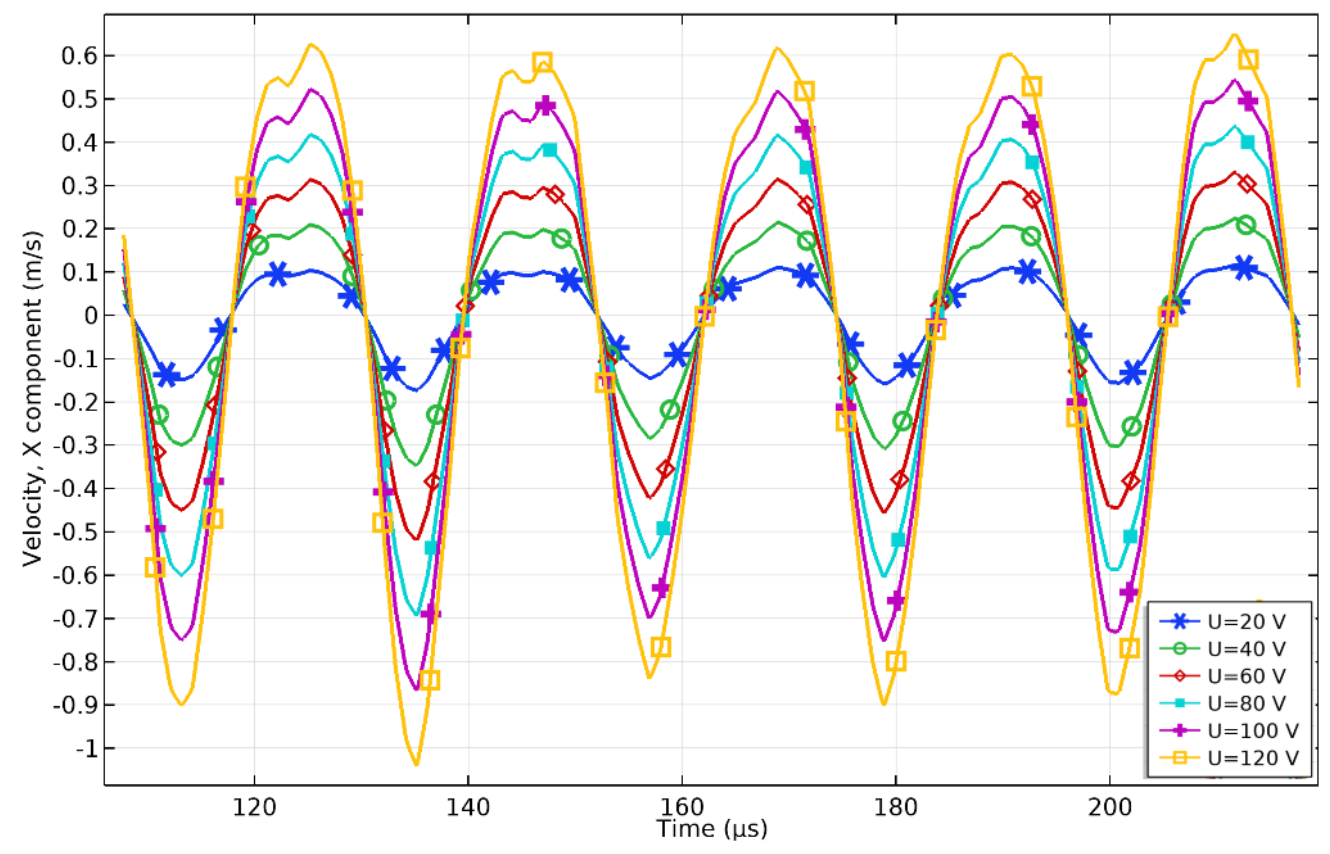

a

Fig. 7 Velocity characteristics of the contact points; $\mathrm{a}$ - velocity in X direction; $\mathrm{b}$ - velocity in Y direction 


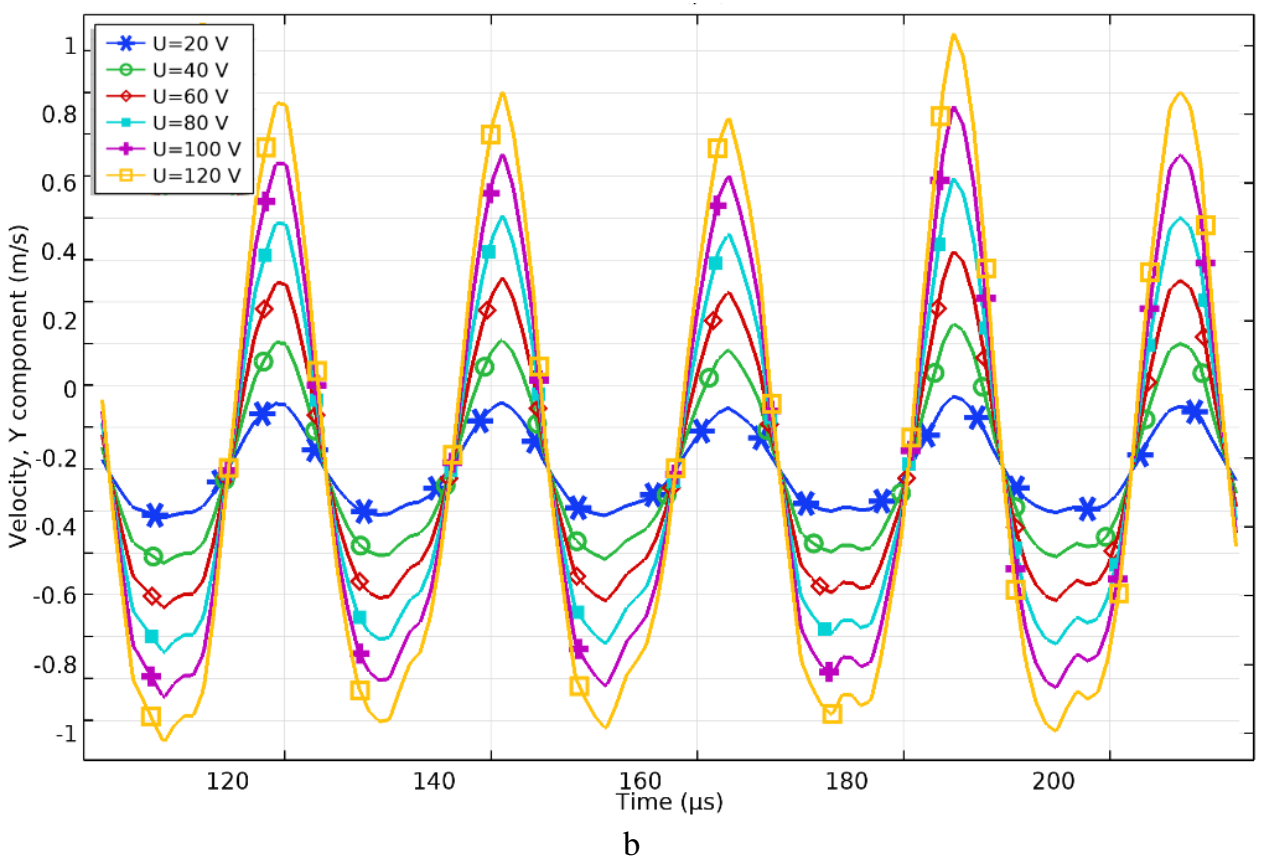

Fig. 7 Continuation

Analysing velocity curves, it can be seen that it has a trapezoid shape showing that velocity fluctuation and acceleration value are small on the crest of the curve (Fig.7). Also, it can be found that the lowest velocities of contact points were obtained at $20 \mathrm{~V}_{p-p}$ and it approximately reached $0.25 \mathrm{~m} / \mathrm{s}$ or $12.5 \mu \mathrm{m} / \mathrm{s} / \mathrm{V}$ in forward and backward direction, respectively. On the other hand, the highest velocity of con tact points in $\mathrm{X}$ and $\mathrm{Y}$ directions was obtained at $120 \mathrm{~V}_{p-p}$ excitation amplitude, and it reached approximately $1.75 \mathrm{~m} / \mathrm{s}$ or $14.6 \mu \mathrm{m} / \mathrm{s} / \mathrm{V}$. Therefore, it can be stated that the velocity characteristics of the contact points confirm the operating principle of the motor and shows that the structure has good dynamic potential and stable as well predictable contact points velocity characteristics.

Displacement characteristics of a contact point in $\mathrm{X}$ and $\mathrm{Y}$ directions at different excitation amplitudes were calculated as well. The results are given in Fig. 8. The stable characteristics were obtained after five periods of operation i.e., as in the previous case. The lowest displacements in both directions were obtained while $20 \mathrm{~V}_{p-p}$ excitation amplitude was applied. The displacements at this excitation amplitude reached approximately $53 \mu \mathrm{m}$ or $2.65 \mu \mathrm{m} / \mathrm{V}$. On the other hand, the highest displacements in both directions were obtained at $120 \mathrm{~V}_{p-p}$ excitation amplitude i.e. approximately $210 \mu \mathrm{m}$ or $1.75 \mu \mathrm{m} / \mathrm{V}$. Analysing the results of the simulation, it can be noticed that the saw tooth-like displacement curve is achieved and becomes biased to the left side (Fig. 8). Numerical simulation reveals that the asymmetrical motion of the contact point is achieved by applying a saw tooth signal, so the inertial principle of rotor driving can be implemented. Also, results showed that the motor is able to provide high displacement amplitudes at low voltage.

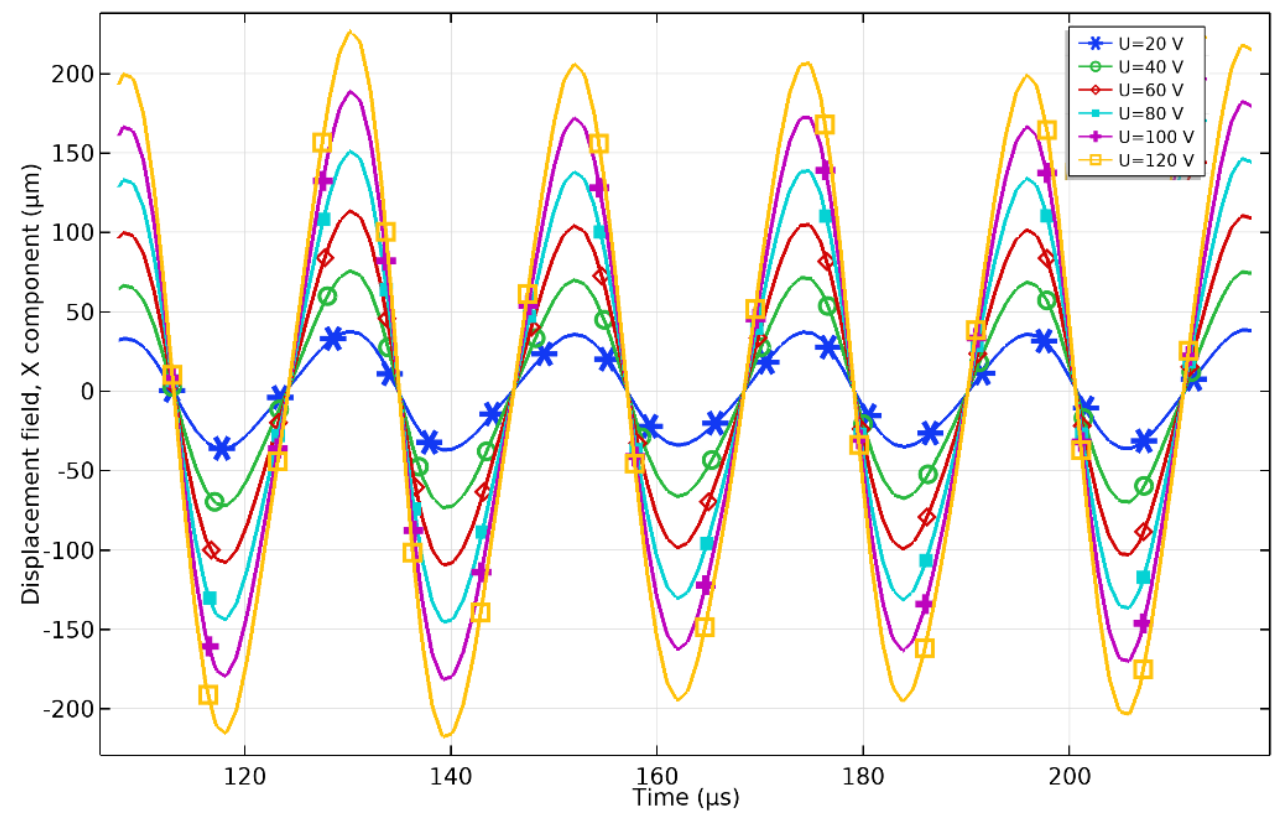

Fig. 8 Displacement characteristics of the contact points; $\mathrm{a}$ - displacement in $\mathrm{X}$ direction; $\mathrm{b}$ - displacement in $\mathrm{Y}$ direction 


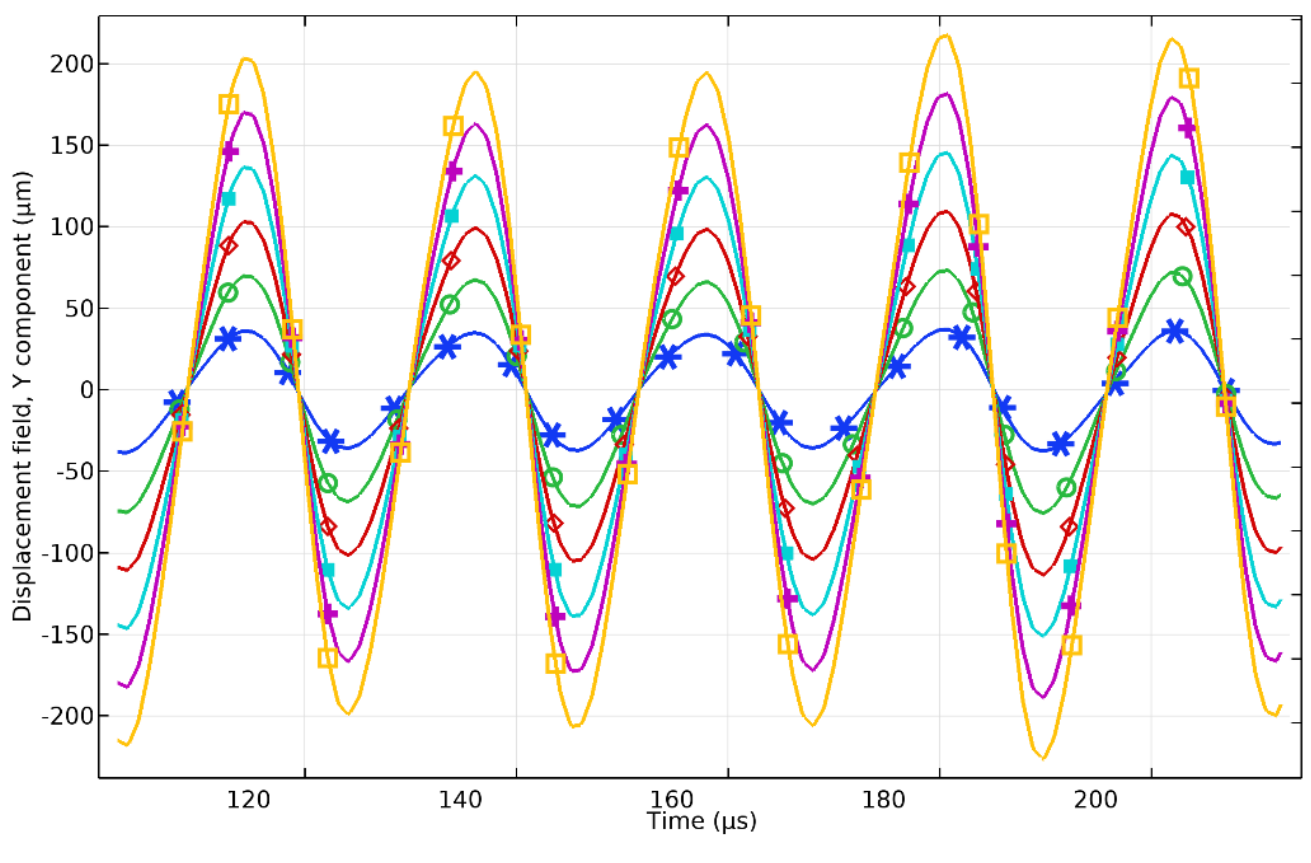

b

Fig. 8 Continuation

\section{Experimental investigation of the motor}

An experimental investigation was performed to validate the operation principle of the motor and to measure electrical and mechanical characteristics. The prototype of the motor (Fig. 9) was made with respect to geometrical and physical characteristics (Table 1 and 2).

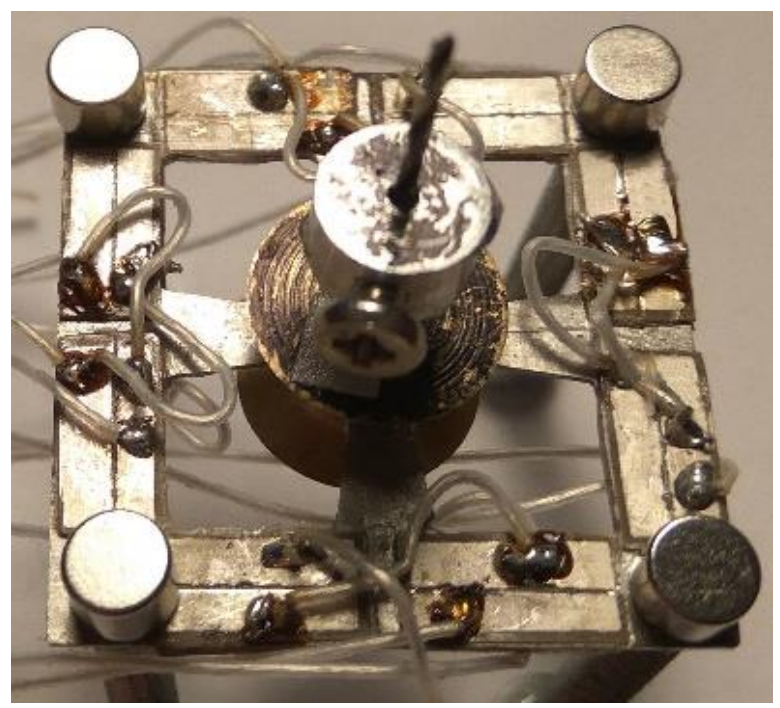

Fig. 9 A prototype of the motor

Firstly, the impedance and phase were measured in the frequency domain. Impedance analyser HP 4192A LF (Hewlett Packard, USA) was used for this purpose. The results of the measurements are given in Fig. 10. Impedancefrequency and phase-frequency characteristics showed that the resonant frequency of the motor is $44.81 \mathrm{kHz}$. The difference between calculated and measured resonant frequencies is $1.593 \mathrm{kHz}$ or $3.43 \%$. The measured mechanical quality factor $Q_{m}$ is 2835.55 . It must be pointed out the measured value of $Q_{m}$ is notably lower compared to the calculated one. The mismatch is mainly caused by neglecting the glue layer in the FEM model and minor differences in material properties. In general, it can be concluded that the measured electrical characteristics of the prototype motor have good agreement with the results of numerical simulation. Experimental investigation of average rotation speed at different excitation voltage amplitudes and preload forces was performed. The experimental setup was built for this purpose (Fig. 11).

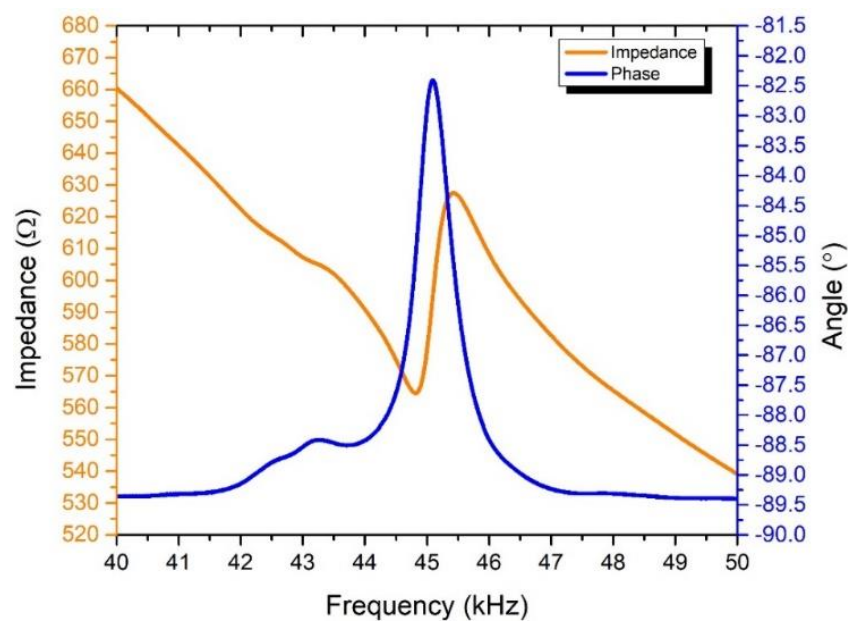

Fig. 10 The measured impedance and phase of the motor versus frequency

The experimental setup consisted of a computer, four-channel function generator WW5064 (Tabor Electronics, Israel), power amplifier E-619 (PI Ceramic GmbH, Germany), four-channel oscilloscope Yokogawa DL2000 (Yokogawa, Japan), and non - contact tachometer UT 372 (Uni-T, China). The average rotation speed of the motor was measured when the excitation voltage amplitude was changed from $20 \mathrm{~V}_{p-p}$ to $120 \mathrm{~V}_{p-p}$. Also, three different preload forces were applied to the rotor. The results of the measurement are given in Fig. 12. 


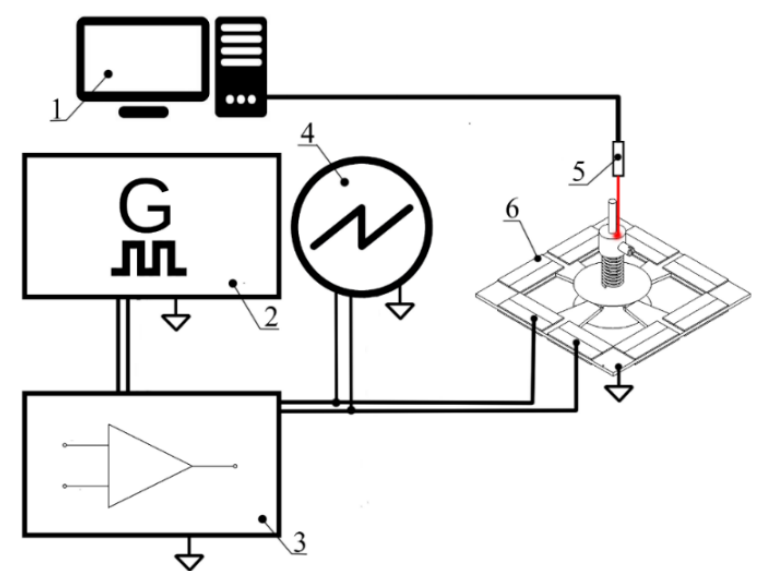

Fig. 11 Scheme of the experimental setup; 1 - a computer with data acquisition software; 2 - a four-channel function generator; 3 - a four-channel power amplifier; 4 - oscilloscope; 5 - a non-contact tachometer; 6 - a prototype of the motor

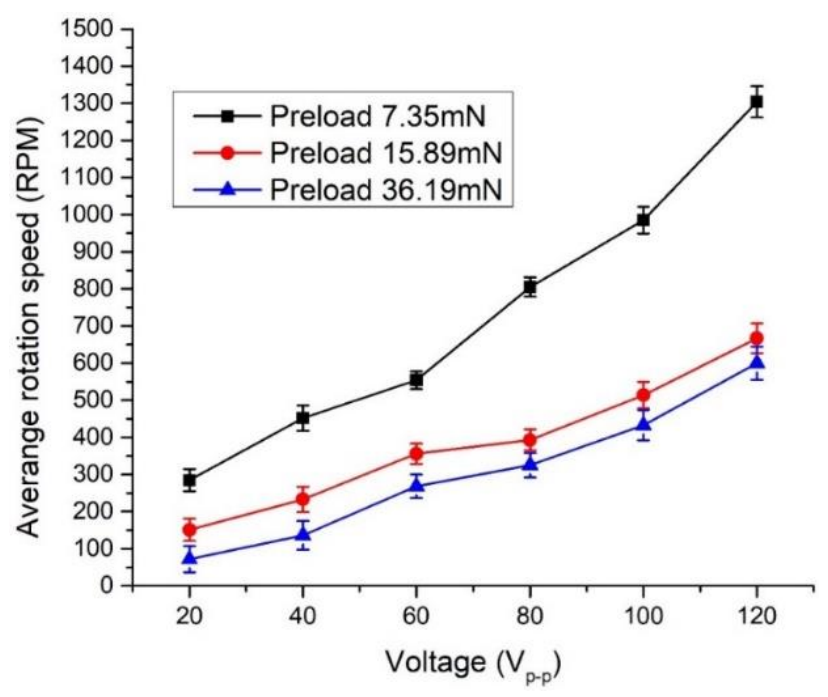

Fig. 12 The average rotation speed of the motor at different excitation voltage amplitudes and preload conditions

It can be seen that the lowest average rotation speed of 72 RPM was obtained when the voltage of $20 \mathrm{~V}_{p-p}$ was used, and a preload force of $36.19 \mathrm{mN}$ was applied. While at the same preload force and $120 \mathrm{~V}_{p-p}$ excitation voltage, the average rotation speed reached 612 RPM. The rotation speed per voltage ratio was 3.6 RPM/V and 5.1RPM/V, respectively. When the preload force was reduced till $15.89 \mathrm{mN}$, the average rotation speeds were increased approximately by $15-22 \%$ while the preload force is $56.1 \%$ lower. The highest average rotation speed was obtained when the preload was $7.35 \mathrm{mN}$. The highest average rotation speed of $1304 \mathrm{RPM}$ obtained at $120 \mathrm{~V}_{p-p}$, while the lowest rotation speed of $285 \mathrm{RPM}$ was obtained at $20 \mathrm{~V}_{p-p}$. Rotation speed per voltage ratio of 10.9 RPM/V and 14.25 RPM/V in this case. When comparing the results of the measurement, it can be pointed out that rotation speed strongly depends on the preload force.

\section{Conclusions}

An inertial piezoelectric rotary motor based on the square-shaped frame was developed. The design of the motor has a flat structure and is scalable. The space required for motor mounting is $625 \mathrm{~mm}^{2}$ and $562.5 \mathrm{~mm}^{3}$ therefore, the proposed motor can be used for applications where mounting volume and surface are critical. The operating principle of the actuator was confirmed by the numerical and experimental study. Numerical investigations showed that motor operation is based on the second in-plane bending mode $(46.403 \mathrm{kHz})$ of the bimorph plates, and asymmetrical vibrations of the waveguides can be achieved when the saw tooth signal is applied. Optimization of the dimensions of the waveguide allowed to maximize the amplitudes of the vibrations of the contact points. Experimental measurement of rotation speed showed that the highest average rotation speed was 1304 RPM when the voltage of $120 \mathrm{~V}_{p-p}$ was applied, and a preload force of $7.35 \mathrm{mN}$ was used. Measures of the average rotation speed showed that the motor can provide stable rotation characteristics at different preload forces.

\section{Funding}

This research was funded by the European Social Fund according to the activity 'Promotion of postdoctoral fellowships studies“" of Measure No. 09.3.3-LMT-K-712

\section{References}

1. Spanner, K.; Koc, B. 2016. Piezoelectric Motors, an Overview. Actuators, 5(1): 1-6. https://doi.org/10.3390/act5010006.

2. Zhao, C. 2010. Ultrasonic motors. Science Press, Beijing. ISBN 978-7-03-029018-9.

3. Shafik, A.; Ben Mrad R. 2016. Piezoelectric Motor Technology: A Review. In: Ru C., Liu X., Sun Y. Nanopositioning Technologies. Springer, Cham. https://doi.org/10.1007/978-3-319-23853-1.

4. Wang, S.; Rong, W.; Wang, L.; Xie, H.; Sun, L.; Mills, J. K. 2019. A survey of piezoelectric actuators with long working stroke in recent years: Classifications, principles, connections and distinctions. Mechanical Systems and Signal Processing 123: $591-605$. https://doi.org/10.1016/j.ymssp.2019.01.033.

5. Hunstig, M.; 2017. Piezoelectric Inertia Motors - A Critical Review of History, Concepts, Design, Applications, and Perspectives. Actuators 6(7): 27-33. https://doi.org/10.3390/act6010007.

6. Hunstig, M.; Hemsel, T.; Sextro, W. 2013. Stick-slip and slip-slip operation of Piezoelectric inertia drives. Part I: Ideal excitation. Sensors and Actuators A., Vol. 200. https://doi.org/10.1016/j.sna.2012.11.012.

7. Hunstig, M.; Hemsel, T.; Sextro, W. 2013. Stick-slip and slip-slip operation of piezoelectric inertia drivesPart II: Frequency-limited excitation, Sensors and Actuators A 200: 79- 89. https://doi.org/10.1016/j.sna.2012.11.043.

8. Tian, X.; Liu, Y.; Deng, J.; Wang, L.; Chen, W. 2020. A review on piezoelectric ultrasonic motors for the past decade: Classification, operating principle, performance, and future work perspectives, Sensors and Actuators, A: Physical 306(92): 111971. https://doi.org/10.1016/j.sna.2020.111971.

9. Gao, X.; Yang, J.; Wu, J.; Xin, X.; Li, Z.; Yuan, X.; Shen, X.; Dong, S. 2020. Piezoelectric actuators and 
motors: materials, designs, and applications, Advanced Materials Technologies 5(1): 1-26. https://doi.org/10.1002/admt.201900716.

10. Zhang, B.; Chen, F.; Li, H.; Du, Z.; Sun, L.; Dong, W. 2018. A friction-inertial-based rotary motor: design, modelling and experiments, Materials 11(6). https://doi.org/10.3390/ma11060918.

11. Shen, D.; Wen, J.; Ma, J.; Hu, Y.; Wang, R.; Li, J. 2020. A novel linear inertial piezoelectric actuator based on asymmetric clamping materials, Sensors and Actuators, A: Physical 303: 111746. https://doi.org/10.1016/j.sna.2019.111746.

12. Wang, L.; Hou, Y.; Zhao, K.; Shen, H.; Wang, Z.; Zhao, C.; Lu, X. 2019. A novel piezoelectric inertial rotary motor for actuating micro underwater vehicles. Sensors and Actuators, A: Physical 295: 428 - 438. https://doi.org/10.1016/j.sna.2019.06.014.

13. Zhang, Y.; Wang, M.; Cheng, Y.; Zheng, D.; Peng, Y. 2019. A stick-slip/inchworm hybrid rotary piezo motor based on a symmetric triangular driving mechanism, Applied Physics Letters 115(130. https://doi.org/10.1063/1.5119000.

14. Wang, J.; Huang, H.; Zhang, S.; Qin, F.; Wang, Z.; Liang, T.; Zhao, H. 2020. Development and analysis of a stick-slip rotary piezoelectric positioner achieving high velocity with compact structure, Mechanical Systems and Signal Processing 145: 106895. https://doi.org/10.1016/j.ymssp.2020.106895.
Y. Yang, A. Čeponis, D. Mažeika, V. Jūrènas

\section{INERTIAL PIEZOELECTRIC ROTARY MOTOR BASED ON LOW PROFILE STATOR WITH TRAPEZOIDAL WAVEGUIDES}

S u m m a r y

Results of numerical and experimental investigations of a novel inertial piezoelectric rotary type motor based on a low profile stator with trapezoidal waveguides. The proposed motor has a simple design and is well scalable. Moreover, the proposed design of the motor allows mount it on a printed circuit board and use it in a small-size mobile positioning and actuating systems. The structure of the stator is based on a square type hollowed steel frame with four straight trapezoidal waveguides that are used to transfer vibrations of the stator to the rotation of the rotor. Piezo ceramic plates are glued on both sides of the stator. The thickness of the assembled stator is $0.9 \mathrm{~mm}$, while the total area needed for stator mounting does not exceed $625 \mathrm{~mm}^{2}$. The driving of the rotor is based on the stick-slip principle, which is induced by excitation of the second inplane bending mode of the four bimorph plates applying two saw tooth waveform signals with a phase difference by $\pi$. The numerical and experimental investigation was carried out to validate the operation principle of the motor and to measure the mechanical and electrical characteristics. The maximum angular rotation speed of 1304 RPM was achieved at a resonance frequency of $44.81 \mathrm{kHz}$ when a preload of $7.35 \mathrm{mN}$ was applied.

Keywords: inertial piezoelectric motor; square frame; thin stator. 